\title{
Foreign body ingestion in children: Single institutional experience in Sri Lanka
}

\author{
Balasubramaniam Branavan $^{1}$, Ranjan Dias ${ }^{2}$, Thanuja Kumari ${ }^{3}$, Malik Samarasinghe ${ }^{2}$
}

Sri Lanka Journal of Child Health, 2014; 43(2): 88-91

\begin{abstract}
Introduction: Foreign body (FB) ingestion in children is a common problem worldwide. Peak incidence is between the ages of 6 months to 4 years and children usually pass the object spontaneously without any symptoms.
\end{abstract}

Objective: To assess the pattern of FB ingestion in the Sri Lankan context.

Method: A descriptive cross sectional study was conducted from April to September 2010 at a leading tertiary care hospital. Data was collected by interviewer administered questionnaire and reviewing Bed Head Tickets.

Results: Peak incidence of FB ingestion occurred between one to four years of age $(50.4 \%)$ with a slight male predominance $(56.6 \%)$. None of the children were mentally challenged. Five of the children who presented with a history of ingestion had aspirated the FB and all of them required bronchoscopy to remove the object, one child also requiring intensive care unit admission. All the aspirated objects were food particles. Button battery $(24.5 \%)$ and coins $(17.0 \%)$ were the commonly ingested foreign bodies. Common source of button battery was the toys with which they were playing. More than half presented to the hospital asymptomatically. One third of children notified their parents about the ingestion. Expectant management was offered to $66 \%$ of the children and all of them recovered uneventfully without any intervention. Upper gastrointestinal endoscopy was used in $12(22.6 \%)$ children to remove the FB.

Conclusions: Commonest source of FB was button batteries from toys. Most children ingested the FB despite mother's care. Although most FB ingestion could be managed expectantly, offering appropriate intervention at the correct time prevents complications. Patient presenting with a history of FB ingestion may have aspirated the FB. As

${ }^{1}$ Research Assistant, ${ }^{2}$ Senior Lecturer, Department of Surgery, Faculty of Medicine, University of Colombo, ${ }^{3}$ Medical Officer, Base Hospital, Tangalle

(Received on 28 August 2013: Accepted after revision on 27 September 2013) aspirated FBs are associated with significant complications, a high degree of suspicion is needed to differentiate ingestion from aspiration.

(Key words: Foreign body ingestion; children; Sri Lanka)

\section{Introduction}

Foreign body (FB) ingestion among children is a common problem worldwide and a leading cause of emergency room visits. Peak incidence of FB ingestion is between the ages of six months and four to six years ${ }^{1-3}$. Unlike adults, FB ingestions mostly occur accidentally in children ${ }^{4}$ who often swallow objects readily available to them such as coins, toy parts and batteries ${ }^{3-5}$. Studies showed that most of the time, swallowed particles will pass spontaneously without any intervention ${ }^{6-7}$.

\section{Objectives}

- $\quad$ To identify the pattern of FB ingestion among children in the Sri Lankan context.

- To describe the management pattern of FB ingestion.

\section{Method}

This is a descriptive cross sectional study conducted between April 2010 and September 2010 at a leading tertiary care children's hospital in Sri Lanka. Ethical clearance was obtained from the hospital ethical review committee. Patients who presented with a history of FB ingestion to the emergency department were recruited to this study after obtaining informed proxy consent. Data was collected by the investigator using an interviewer administered questionnaire. In addition, Bed Head Tickets (BHTs) and other patient health records were reviewed. Data was analysed with SPSS 19 statistical software.

\section{Results}

Fifty three children aged between 9 months to 11 years (mean 3.88 years, SD 2.72 years) presented with a history of FB ingestion. Peak incidence was noted between one to four years of age $(50.4 \%)$. Male predominance was noted in this study population $(56.6 \%)$. None of the children were 
mentally challenged. Majority of these children were looked after by mother at the time of incident $(83.0 \%)$. The age groups of the children are shown in Table 1.

Table 1

Age groups of patients presenting with a history of $F B$ ingestion

\begin{tabular}{|c|c|}
\hline Age group & $\begin{array}{c}\text { No. of children } \\
(\mathbf{\%})\end{array}$ \\
\hline Less than 1 year & $06(11.3)$ \\
\hline $\begin{array}{c}\text { 1year and one month }-2 \\
\text { years }\end{array}$ & $13(24.5)$ \\
\hline $\begin{array}{c}\text { 2years and one month }-4 \\
\text { years }\end{array}$ & $14(26.4)$ \\
\hline $\begin{array}{c}\text { 4 years and one month }-6 \\
\text { years }\end{array}$ & $10(18.9)$ \\
\hline $\begin{array}{c}\text { 6 years and one month }-8 \\
\text { years }\end{array}$ & $06(11.3)$ \\
\hline More than 8 years & $04(07.6)$ \\
\hline Total & $\mathbf{5 3 ( 1 0 0 \% )}$ \\
\hline
\end{tabular}

All children ingested the FBs accidentally and no case of intentional ingestion by self or others was reported. Button batteries (24.5\%), coins (17.0\%) and impacted organic particles (13.2\%) were the common foreign bodies identified following ingestion. Main source for the button batteries was from toys. Majority of the FBs ingested were nonsharp $(77.4 \%)$ in nature, while $18.9 \%$ contained a pointed edge. Most of the time, child was playing $(69.8 \%)$ at home while swallowing the FB.

In $39.6 \%$ instances, the child was directly brought to the emergency department of our institution while in $20.8 \%$ and $24.6 \%$ instances child was referred by a general practitioner or from a base hospital respectively. Half of the study population presented to the emergency department without any symptoms. Nineteen children (35.8\%) informed their parents regarding their FB ingestion prior to developing any symptom. Another 15 children $(28.3 \%)$ were witnessed by a second party while swallowing the FB and most of them were noted by the mother $(17.0 \%)$. Common symptoms reported were vomiting $(13.2 \%)$, and cough $(11.3 \%)$. The presentations of the children ingesting various FBs are shown in Table 2.

Table 2: Presentations of the children ingesting various foreign bodies

\begin{tabular}{|c|c|c|c|c|c|c|c|}
\hline $\begin{array}{c}\text { FB } \\
\text { ingested }\end{array}$ & $\begin{array}{c}\text { Asymptomatic } \\
\text { No. (\%) }\end{array}$ & $\begin{array}{c}\text { Cough } \\
\text { No. (\%) }\end{array}$ & $\begin{array}{c}\text { Vomiting } \\
\text { No. (\%) }\end{array}$ & $\begin{array}{c}\text { Difficulty in } \\
\text { breathing } \\
\text { No. (\%) }\end{array}$ & $\begin{array}{c}\text { Drooling } \\
\text { of saliva } \\
\text { No. (\%) }\end{array}$ & $\begin{array}{c}\text { Abdominal } \\
\text { pain } \\
\text { No. (\%) }\end{array}$ & $\begin{array}{c}\text { Reduced } \\
\text { feeding } \\
\text { No. (\%) }\end{array}$ \\
\hline $\begin{array}{c}\text { Button } \\
\text { battery }\end{array}$ & $12(22.6)$ & 0 & $01(1.9)$ & $01(1.9)$ & $01(1.9)$ & 0 & 0 \\
\hline Coin & $04(07.6)$ & $01(1.9)$ & $01(1.9)$ & 0 & $01(1.9)$ & $02(3.8)$ & 0 \\
\hline $\begin{array}{c}\text { Food } \\
\text { particle }\end{array}$ & $01(01.9)$ & $03(5.7)$ & $02(3.8)$ & $03(5.7)$ & $01(1.9 \%)$ & 0 & 0 \\
\hline $\begin{array}{c}\text { Metal } \\
\text { piece }\end{array}$ & $05(09.4)$ & 0 & 0 & 0 & 0 & 0 & 0 \\
\hline Nail & $03(05.7)$ & 0 & $01(1.9)$ & 0 & 0 & 0 & 0 \\
\hline Pin & $02(03.8)$ & $01(1.9)$ & 0 & 0 & 0 & 0 & 0 \\
\hline Magnet & $01(01.9)$ & 0 & 0 & 0 & 0 & 0 & 0 \\
\hline Plastic & $03(05.7)$ & $01(1.9)$ & $03(5.7)$ & 0 & 0 & $01(1.9)$ & $01(1.9)$ \\
\hline Marble & $01(01.9)$ & 0 & 0 & 0 & 0 & 0 & 0 \\
\hline
\end{tabular}

Expectant management with stool inspection was offered to $35(66 \%)$ children. One child was brought to hospital following a coin passing through the colostomy and there was no further intervention. Intervention was needed only in 17 (32.1\%) patients. Five $(9.4 \%)$ children presenting with a history of FB ingestion had really aspirated the FB. Bronchoscopy was offered to remove aspirated FB in all 5 cases. Aspirated material was mainly organic particles such as rambutan seeds and peanuts. One of the children who had aspirated the FB was treated in the intensive care unit (ICU) with ventilator support. Upper gastrointestinal endoscopy (UGIE) was offered to 12 children $(22.6 \%)$ for the removal of FB. Indications for UGIE were removal of FB lodging in the oesophagus (13.2\%) and non-moving object with serial radiograph monitoring $(9.4 \%)$. The relationship of the nature of the objects to the management is shown in Table 3.

Table 3: Relationship of nature of the objects to its management

\begin{tabular}{|c|c|c|c|}
\hline Nature of object & Expectant & UGIE & Bronchoscopy \\
\hline Non sharp & $26(49.1 \%)$ & $06(17.0 \%)$ & $05(9.4 \%)$ \\
\hline Pointed edge & $07(13.2 \%)$ & $01(05.7 \%)$ & 0 \\
\hline Sharp & $02(03.8 \%)$ & 0 & 0 \\
\hline
\end{tabular}


Children who were managed expectantly passed the object through gastrointestinal tract without any complication. One child developed a retropharyngeal abscess following the ingestion of a fish bone which was lodged in the oesophagus. It was successfully removed by endoscopy and child recovered uneventfully.

\section{Discussion}

FB ingestion is a commonly encountered problem among the paediatric population. Our study concludes that the peak incidence of accidental foreign body ingestion occurs between one to four years of age with a slight male predominance. Button batteries and coins were the commonly ingested foreign bodies by our children. More than half of them presented to hospital without any symptom. One third of the children informed their parents about the ingestion prior to developing any symptoms. Expectant management was offered to two thirds of the children and they recovered uneventfully. Rest of the children underwent some form of intervention while none required any surgical procedure. Five children with a history of FB ingestion had aspirated the FB and one of them needed ICU care.

Peak age for paediatric FB ingestion is reported to be between 6 months and 4 to 6 years of age ${ }^{1-3}$. Our children also adhered to that age group. Slight male predominance was noted in our study and similar pattern is described in the literature ${ }^{3,8}$. Literature review shows that $98 \%$ of paediatric $\mathrm{FB}$ ingestions are accidental ${ }^{4}$ and all of our cases were accidental.

Coin is the commonest object ingested by children where fish does not represent a large proportion of the diet and fish bone becomes the number one object in countries where fish represent a large proportion of $\operatorname{diet}^{9}$. Cheng $\mathrm{W}$ et al from China reported that coin and fish bone were the most common particles ingested by children ${ }^{1}$. Button battery was the commonest object swallowed by our children followed by coins. Two cases of fish bone ingestion were reported in our study.

Management of FB ingestion depends on various factors such as nature of the $\mathrm{FB}$, time since ingestion and site of $\mathrm{FB}$ in the gastrointestinal tract $^{3,10}$. A retrospective review by Arana $A$ et al found that $50 \%$ of the children with confirmed $\mathrm{FB}$ ingestion were found to be asymptomatic ${ }^{11}$. Expectant management with the stool inspection for suspected foreign body and serial radiography would be adequate most of the time ${ }^{1,2-5.9}$. Kay M et al states that $80-90 \%$ of FB ingested will usually pass spontaneously without any intervention while only $10-20 \%$ will require endoscopic removal ${ }^{12}$.
Only less than $1 \%$ needs surgical intervention ${ }^{12}$. Most of our patients were also managed expectantly while only one third of the patients needed some form of intervention. None of our children required surgical intervention.

Louie et al states that FB aspiration is less common than ingestion ${ }^{13}$. He also says that food particles are the most common objects identified following aspiration and that the pattern of food types varies regionally ${ }^{13}$. Peanuts were the commonly described food particles aspirated by children ${ }^{13}$. Midulla $\mathrm{F}$ et al also found most of the aspirated FBs were food particles ${ }^{14}$. Five of our children who presented to the emergency department with a history of foreign body ingestion had really aspirated the objects, mostly food particles. Suspicion of aspiration should be considered even if the patient comes with a history of FB ingestion.

\section{Conclusions}

- Major source of button batteries was toys with which children were playing.

- Most children ingested the FB despite mother's care.

- Though most FB ingestions could be managed expectantly, offering appropriate intervention at the correct time prevents complications.

- Patients presenting with a history of FB ingestion could have aspirated the FB. A high index of suspicion is needed.

\section{Reference}

1. Cheng W, Tam PK. Foreign-body ingestion in children: experience with 1265 cases. Journal of Pediatric Surgery1999; 34(10): 1472-6. http://dx.doi.org/10.1016/S00223468(99)9010 $\underline{6-9}$

2. Panieri E, Bass $\mathrm{OH}$. The management of ingested foreign bodies in children: a review of 663 cases. European Journal of Emergency Medicine 1995; 2(2): 83-7. http://dx.doi.org/10.1097/0006311019950600$\underline{00005}$

3. Conners PG. Pediatric foreign body ingestion. Available from:

http://emedicine.medscape.com/article/801821 -overview (accessed 30 July 2013).

4. Chung S, Forte V, Campisi P. A review of paediatric foreign body ingestion and management. Clinical Pediatric Emergency Medicine 2010; 11(3): 225-30. http://dx.doi.org/10.1016/j.cpem.2010.06.002 
5. Jayachandra S, Eslick GD. A systematic review of paediatric foreign body ingestion: Presentation, complications, and management. International Journal of Pediatric Otorhinolaryngology 2013; 77(3): 311-7.

http://dx.doi.org/10.1016/j.ijporl.2012.11.025

6. Eisen GM, Baron TH, Dominitz JA, et al. Guideline for management of ingested foreign bodies. Gastrointestinal Endoscopy 2002; 55 (7): 802-6.

http://dx.doi.org/10.1016/S00165107(02)7040 7-0

7. Antoniou D, Christopoulos G. Management of foreign body ingestion and food bolus impaction in children: a retrospective analysis of 675 cases. Turkish Journal of Pediatrics 2011; 53(4): 381-7.

8. Louie MC, Bradin S. Foreign Body Ingestion and Aspiration. Pediatrics in Review 2009; 30(8): 295-301

http://dx.doi.org/10.1542/pir.30-8-295

9. Uyemura MC. Foreign body ingestion in children. American Family Physician 2005; 72(2): 287-91.
10. Chen MK, Beierle EA. Gastrointestinal foreign bodies. Pediatric Annals 2001; 30(12): 736-42.

11. Arana A, Hauser B, Hachimi-Idrissi S, Vandenplas Y. Management of ingested foreign bodies in childhood and review of the literature. European Journal of Pediatrics 2001; 160(8): 468-72. http://dx.doi.org/10.1007/s004310100788

12. Kay M, Wyllie R. Pediatric foreign bodies and their management. Current Gastroenterological Reports 2005; 7(3): 2128.

http://dx.doi.org/10.1007/s11894-005-0037

13. Louie MC, Bradin S. Foreign body ingestion and aspiration. Pediatrics in Review 2009; 30(8): 295-308.

http://dx.doi.org/10.1542/pir.30-8-295

14. Midulla F, Guidi R, Barbato A, Capocaccia P, Forenza N, Marseglia G, et al. Foreign body aspiration in children. Foreign body aspiration in children 2005; 47(6): 663-8. 